\title{
Correlation and Path Coefficient Analysis in Yield and Yield-Related Components of Black Cumin (Nigella Sativa L.) Accessions, at Jimma, Southwest Ethiopia
}

\author{
Zigyalew Gashaw ${ }^{(D},{ }^{1}$ Wosene Gebreselassie, ${ }^{2}$ and Girma Hailemichael ${ }^{2}$ \\ ${ }^{1}$ Department of Horticulture, Injibara University, P.O. Box 40, Injibara, Ethiopia \\ ${ }^{2}$ Department of Horticulture and Plant Science, Jimma University, P.O. Box 378, Jimma, Ethiopia \\ Correspondence should be addressed to Zigyalew Gashaw; zigyalewgashaw@gmail.com
}

Received 6 September 2020; Accepted 15 December 2020; Published 28 December 2020

Academic Editor: Cristina Patan

Copyright (c) 2020 Zigyalew Gashaw et al. This is an open access article distributed under the Creative Commons Attribution License, which permits unrestricted use, distribution, and reproduction in any medium, provided the original work is properly cited.

\begin{abstract}
Many research works have been done on black cumin focusing on its nutritional and medicinal properties. But, there is inadequate information on the association of yield and yield-constituting traits of black cumin to improve its production. Therefore, correlation analysis was made on thirty-six black cumin accessions evaluated at Jimma in simple lattice design during 2016, to quantify the relationship between traits. The result of the analysis showed that seed yield ha $^{-1}$ had positive and highly significant correlation with number of effective capsules (0.88), secondary branches (0.73), plant height (0.72), total branches (0.71), steam thickness (0.58), primary branches (0.52), tertiary branches (0.52), harvesting index (0.47), and biological yield (0.43). Path coefficient analysis revealed that harvesting index, biological yield, and number of effective capsules exerted high and favorable direct contribution to seed yield at phenotypic level, whereas harvesting index, biological yield, primary and tertiary branches, number of effective capsules, and stem thickness showed positive direct effect at genotypic level. The favorable direct effects of these traits on grain yield indicate that keeping other variables constant, improvement of these traits will increase black cumin yield. Therefore, these traits should be kept in mind in the future breeding program of black cumin.
\end{abstract}

\section{Introduction}

Black cumin (Nigella sativa L.) belongs to the Ranunculaceae family in the order of Ranales, which is a large family containing about 70 genera and over 300 species. It is also classified under the 14 species of annual herbs in the genus Nigella [1]. It is originated in Egypt and East Mediterranean; the cultivation of black cumin can be traced back more than 3,000 years [2]. But it is broadly cultivated in other parts of the world including sub-Saharan Africa especially Ethiopia $[3,4]$.

The use of black cumin has been testified both in religious and scientific evidence. The importance of $N$. sativa to the Muslims came from the saying of the Prophet Mohammed where he said there is medicine for every disease except death [5]. And also as mentioned in the Holy Bible both in the old and in the new testaments, cumin was used as a currency to pay tithe to the ancient Rome and Greece priests [6]. Researches from around the globe are also giving increasing support to black cumin's widespread healing powers. It was found out that the constituents of the seed have unique chemical properties with more than 100 different chemical components $[7,8]$. Due to richness in a number of chemicals, black cumin is claimed cure of all diseases except death and aging [9]. Moreover, in Ethiopia, it is commonly used as ingredient in different homemade food items such as Berbere (local spice of stew), bread, and katicala (local alcoholic beverage) and as preservative for butter [10]. This age-old practice of using plant resources in traditional medicines still exists in the rural areas of Ethiopia.

Even though production and land coverage of black cumin have been increasing, the productivity is still less than $300 \mathrm{~kg}$ per hectare. From several problems accountable for 
the continued low productivity and production of black cumin, lack of improved seed is the principal factor. Due to the increased demand of black cumin seed for local consumption and other importance, such as oil and oleoresin for medicinal purposes, its export market improving its seed yield and genetic improvement must be undertaken.

But seed yield is a composite trait whose production is influenced by its constituent traits directly or indirectly. Breeder is certainly concerned in investigating the extent and type of relationship of such traits for they contribute valuable information in breeding for yield [11]. Knowledge of the association of yield and its constituent traits will allow a breeder to know how the selection pressure employed by him on one trait will cause variations in other traits. Thus, quantification of the association between yield and its constituents is critical in breeding for a certain crop. For the purpose of quantification of interactions among traits in crop plants, correlation and regression analyses are used [12] for the breeder to realize the nature and extent of the relationship between traits which are commonly used to achieve better yield of the crop. Assessing genotypic and phenotypic correlation coefficients with yield interrelated traits is, therefore, significant to utilize the available variability through selection. Correlation is a logical step towards a clear sympathetic of the type of plant traits [11]. Correlation analysis measures the relationships between any given pair of traits without regard to cause/effect association [12].

However, research on the association of black cumin yield and yield-component traits is unsatisfactorily conducted in Ethiopia. As a result, there is not enough information on phenotypic relationship and direct and indirect effect of various characters among yield and yield components of black cumin to measure the relative importance of each variable. Therefore, the objective of this study was to quantify the phenotypic and genotypic relationship and to evaluate the direct and indirect effect of various traits among yield and yield constituents of black cumin accessions conserved in the Institute of Biodiversity Conservation (IBC), in order to gain illustrative results for efficient future selection and enhancement programs.

\section{Materials and Methods}

The experiment was conducted at Jimma, Eladale Research Site, which is located $350 \mathrm{~km}$ south-west of Addis Ababa, Ethiopia. The site is situated at a latitude of $7^{\circ} \mathrm{S} 42^{\prime} 9^{\prime \prime} \mathrm{N}$ and longitude $36^{\circ} 47^{\prime} 6^{\prime \prime} \mathrm{E}$ and an elevation of $1753 \mathrm{~m}$ above sea level. The area receives an average annual rainfall of $1559 \mathrm{~mm}$ with maximum and minimum temperatures of $26.8^{\circ} \mathrm{C}$ and $13.6^{\circ} \mathrm{C}$, respectively. Average maximum and minimum relative humidity of the area are 67.5 and $37.9 \%$, respectively. The soil of the experimental site is reddish brown clay, classified as Nitisol with $\mathrm{pH}$ range of 5.0 to 6.0 [13].

Thirty-six black cumin accessions were used as an experimental material; these thirty-three accessions were kindly provided by IBC which were collected from different regions of Ethiopia. In addition, three released cultivars, that is, Dershaye, Aeden, and Darbera, were provided by Gera Agricultural Research Center. Genotypes are listed in Table 1.

2.1. Experimental Design and Field Management. The experiment was laid out in $6 \times 6$ lattice design with two replications. The total land used for the experiment is $285 \mathrm{~m}^{2}$. Each block consisted of 36 plots and the dimension of each plot was $1 \mathrm{~m} \times 2 \mathrm{~m}\left(2 \mathrm{~m}^{2}\right)$ having a plot to plot and block-toblock distances of $0.5 \mathrm{~m}$ and $1 \mathrm{~m}$, respectively. In a plot, there are four rows spaced $25 \times 15 \mathrm{~cm}$ between rows and plants, respectively. The treatments were randomly allotted in each block.

The land was ploughed three times with harrowing and disking. The seeds were sown in late September 2016 by considering residual soil moisture at $3 \mathrm{~cm}$ depth [14]. The first irrigation was done exactly after sowing and subsequent irrigations were done once in every 2-5 days. Fertilization and other management practices were applied [14].

2.1.1. Data Collection. Data collection was done in plot and in plant basis. So the variables were gathered from five randomly selected plants from the middle rows and from the middle row itself at each replication at the required stage. These variables are expressed below.

Data are collected in plot basis:

(i) Days to $50 \%$ emergence: number of days from date of sowing to when $50 \%$ of the seedlings appeared above the ground level.

(ii) Days to blooming: days from the date of sowing to $50 \%$ bud initiation by observing the whole plants grown at each plot every morning.

(iii) Days to $50 \%$ flowering: days when $50 \%$ of the plants in a plot get flowered.

(iv) Days to maturity: the number of days from date of emergence to when the plant changed from dark green to brown-yellow colour, $90 \%$ of the capsules changed to yellow and when the capsule begun to wither.

(v) Biological yield ( $\mathrm{kg}$ ): it was determined by taking the total above ground whole plant parts harvested from the two central rows of each experimental plot $\left(50 \mathrm{~cm} \times 2 \mathrm{~m}^{2}\right)$ weighed in Gram after dried for three days in open sun then converted to kilograms $\cdot \mathrm{ha}^{-1}$.

(vi) Seed yield per ha ${ }^{-1}(\mathrm{~kg})$ : seed yield was determined by harvesting plants from the net middle plot area $50 \mathrm{~cm} \times 2 \mathrm{~m}^{2}$ to avoid border effects. Seeds, which were obtained from the corresponding net plot, were cleaned manually. After sun dried 8 to $10 \%$ moisture content, it was weighed in grams by using sensitive balance and recorded as mean values of seed yield per hectare after being converted to kilograms.

(vii) Harvest index per plot (\%): it was estimated by dividing grain yield per plot to biological yield per 
TABLE 1: List of the black cumin (N. sativa) accessions with their passport data.

\begin{tabular}{|c|c|c|c|c|c|}
\hline Accession & Region & Zone & Latitude & Longitude & Altitude \\
\hline 9067 & Amhara & Mirab Gojam & $11-41-08-\mathrm{N}$ & $37-01-12-\mathrm{E}$ & 1840 \\
\hline 9068 & Amhara & Mirab Gojam & $11-45-40-\mathrm{N}$ & $37-05-4-\mathrm{E}$ & 1854 \\
\hline 9069 & Amhara & Mirab Gojam & $10-38-48-\mathrm{N}$ & $37-05-09-\mathrm{E}$ & 2002 \\
\hline 9071 & Amhara & Mirab Gojam & $10-38-21-\mathrm{N}$ & $37-05-13-E$ & 1970 \\
\hline 90505 & Amhara & Misrak Gojam & $10-20-00-\mathrm{N}$ & $38-00-00-\mathrm{E}$ & NA \\
\hline 90506 & Amhara & Misrak Gojam & $10-20-00-\mathrm{N}$ & $38-00-00-\mathrm{E}$ & NA \\
\hline 90510 & Oromia & Mirab Shewa & $09-10-00-\mathrm{N}$ & $37-50-00-\mathrm{E}$ & NA \\
\hline 207538 & Amhara & Semen Gondar & $12-20-00-\mathrm{N}$ & $37-14-00-\mathrm{E}$ & NA \\
\hline 207539 & Amhara & Semen Gondar & $12-20-00-\mathrm{N}$ & $37-14-00-\mathrm{E}$ & NA \\
\hline 208032 & Amhara & Semen Gondar & $12-20-00-\mathrm{N}$ & $37-14-00-\mathrm{E}$ & NA \\
\hline 208771 & Oromia & Mirab Wellega & $37-56-25-\mathrm{N}$ & $38-67-11-\mathrm{E}$ & NA \\
\hline 212859 & Oromia & Bale & $07-01-00-\mathrm{N}$ & $39-59-00-\mathrm{E}$ & NA \\
\hline 223069 & Amhara & Misrak Gojam & $11-00-08-\mathrm{N}$ & $37-00-11-\mathrm{E}$ & NA \\
\hline 223071 & Benishangul Gumuz & Metekel & $11-00-00-\mathrm{N}$ & $35-45-45-\mathrm{E}$ & NA \\
\hline 229806 & Benishangul Gumuz & Asosa & $10-03-44-\mathrm{N}$ & $34-32-50-\mathrm{E}$ & NA \\
\hline 236832 & Oromia & Mirab Shewa & $38-01-00-\mathrm{N}$ & $38-05-00-\mathrm{E}$ & 2320 \\
\hline 242223 & Tigray & Mirabawi & $14-06-75-\mathrm{N}$ & $38-27-89-\mathrm{E}$ & 2080 \\
\hline 242224 & SNNP & Arbaminch & $06-06-67-\mathrm{N}$ & $37-66-67-E$ & 2170 \\
\hline 242225 & SNNP & Arbaminch & $06-06-67-\mathrm{N}$ & $37-66-67-\mathrm{E}$ & 1800 \\
\hline 242226 & SNNP & Soddo & $06-51-10-\mathrm{N}$ & $37-45-40-\mathrm{E}$ & 1800 \\
\hline 242227 & SNNP & Soddo & $10-54-32-\mathrm{N}$ & $39-47-29-\mathrm{E}$ & 1800 \\
\hline 242832 & Oromia & Borena & $04-58-00-\mathrm{N}$ & $38-13-00-\mathrm{E}$ & 2280 \\
\hline 242843 & Oromia & Arssi & $07-32-08-\mathrm{N}$ & $39-32-11-\mathrm{E}$ & 2155 \\
\hline 242846 & Amhara & Semen Gonder & $07-35-87-\mathrm{N}$ & $39-29-33-\mathrm{E}$ & 2360 \\
\hline 244653 & Amhara & Semen Gondar & $12-50-00-\mathrm{N}$ & $37-35-00-\mathrm{E}$ & 1872 \\
\hline 244654 & Amhara & Semen Gondar & $12-50-00-\mathrm{N}$ & $37-05-00-\mathrm{E}$ & 1821 \\
\hline 242838 & Oromia & Arssi & $07-35-71-\mathrm{N}$ & $39-32-29-\mathrm{E}$ & 2355 \\
\hline 90514 & Benishangul Gumuz & Metekel & $11-00-00-\mathrm{N}$ & $35-45-45-\mathrm{E}$ & NA \\
\hline 229808 & Benishangul Gumuz & Metekel & & & 1700 \\
\hline 20226 & Oromia & Mirak (jimma) & $08-42-31$ & $36-26-41$ & 1499 \\
\hline 20432 & Tigray & Mehakel & $14-15-22$ & $39-06-22$ & 2014 \\
\hline 20434 & Tigray & Semen & $14-08-49$ & $38-24-42$ & 1962 \\
\hline 20435 & Tigray & Mibraka & $14-00-58$ & $39-27-20$ & 2214 \\
\hline Aden & Highland areas & Bale, Arsi and S/Gonder zones & NA & NA & $1800-2500$ \\
\hline Deribera & Highland areas & Bale, Arsi and S/Gonder zones & NA & NA & $1800-2500$ \\
\hline Dirshaye & Highland areas & Bale, Arsi and S/Gonder zones & NA & NA & $1800-2500$ \\
\hline
\end{tabular}

NA: not available.

plot. It is a ratio of grain yield to the above ground biomass yield.

Data collected on plant basis:

(i) Plant height $(\mathrm{cm})$ : average height in centimeter measured from ground level to the tip of the plant.

(ii) Number of branches per plant: number of primary, secondary, and tertiary branches were recorded by counting branches from respective plant parts raised from the main stem as primary branches, branches raised from primary branches taken as secondary and branches raised from secondary branch taken as tertiary branches which were recorded at maturity stage from five randomly taken plants.

(iii) Number of capsules per plant: the average number of seed bearing capsules from the five tagged plants.

(iv) Number of seeds per capsule: the actual total count of seeds per capsule taken from five randomly taken capsules per plant. (v) 1000-seed weight (g): it was determined from the seed obtained from each of five tagged plants, dried in the sun to 8 to $10 \%$ moisture content by using moisture tester and thereafter weighed by analytical balance and counted with a seed counter and the average weight was expressed in grams.

\subsection{Data Analysis}

2.2.1. Analysis of Variance (ANOVA). The data collected for each quantitative trait was subjected to analysis of variance (ANOVA) for simple lattice design. Normality of each data was checked before the analysis. The result revealed that all the traits showed normality. Analysis of variance for each character was computed using the standard statistical procedure of Gomez and Gomez [15] and using statistical software SAS 9.3 [16]. Efficiency of the lattice design relative to RCBD was checked and, in most of the response variables, the lattice was found to be more efficient than that of the RCBD. After testing the ANOVA assumptions, treatment 
means were tested for significance (LSD) at 5\% probability levels.

\section{Results}

3.1. Phenotypic Correlation Coefficients of 36 Accessions. Assessment of associations among different characters revealed that some of the characters are positively correlated, while others are negatively correlated indicating that improving or increasing specific character will have positive or negative influence on the other characters in such degree apparent from the correlation coefficients (Table 2).

Phenotypic correlation (Table 2 above diagonal) showed that seed yield $\mathrm{ha}^{-1}$ had a highly significant correlation with number of effective capsules per plant $\left(0.83^{* *}\right)$, number of total branches $\left(0.68^{* *}\right)$, plant height $\left(0.66^{* *}\right)$, number of secondary branches $\left(0.66^{* *}\right)$, plant harvesting index $\left(0.53^{* *}\right)$ number of primary branches $\left(0.53^{* *}\right)$, steam thickness $\left(0.52^{* *}\right)$ number of tertiary branches $\left(0.49^{* *}\right)$, and biological yield $\left(0.40^{* *}\right)$ (Table 2$)$.

Days to emergence highly correlated with days to harvest $\left(0.34^{* *}\right)$ and also significantly correlated with biological yield $\left(0.28^{*}\right)$ and $50 \%$ flowering date $\left(0.23^{*}\right)$. It also had a positive correlation with blooming (0.19), thousand seed weight (0.06), number of secondary branches (0.02), and number of seeds per capsule (0.00) and also negatively and significantly correlated with harvesting index $\left(-0.27^{*}\right)$, negatively correlated with plant height $(-0.15)$, number of tertiary branches $(-0.13)$, number of effective capsules per plant $(-0.08)$, stem thickness $(-0.06)$, seed yield ha ${ }^{-1}$ $(-0.04)$, number of total branches per plant $(-0.02)$, and number of primary branches $(-0.01)$ (Table 2$)$.

Days to blooming had highly significant correlation with $50 \%$ flowering $\left(0.58^{* *}\right)$ and days to harvest $\left(0.58^{* *}\right)$ but positively correlated with the number of primary branches (0.14) and stem thickness (0.13). It also had highly significant negative correlation with tertiary branches $\left(-0.45^{* *}\right)$ and also negative correlation with number of total branches per plant $(-0.17)$, number of effective capsules per plant $(-0.17)$ and number of secondary branches $(-0.13)$, number of seeds per capsule $(-0.09)$, thousand-seed weight $(-0.09)$, biological yield $(-0.08)$, and plant height $(-0.03)$ and negatively significantly correlated with seed yield $\mathrm{ha}^{-1}\left(-0.29^{*}\right)$ (Table 2).

Days to $50 \%$ flowering had a highly significant correlation with harvesting date $\left(0.64^{* *}\right)$. It had positive correlation with primary branches (0.15), stem thickness (0.05), and biological yield (0.01) but highly negatively correlated with tertiary branch $\left(-0.45^{* *}\right)$ and negatively correlated other traits studied and mentioned in the table. This might be due to flowers raised from tertiary branch is mostly delayed to flower once with primary branches and secondary branches (Table 2).

The number of primary branches had highly significant correlation with stem thickness $\left(0.80^{* *}\right)$, number of secondary branches $\left(0.74^{* *}\right)$, number of total branches $\left(0.73^{* *}\right)$, plant height $\left(0.72^{* *}\right)$, number of effective capsules per plant $\left(0.63^{* *}\right)$, seed yield ha ${ }^{-1}\left(0.53^{* *}\right)$, biological yield $\left(0.34^{* *}\right)$, and number of tertiary branches $\left(0.31^{* *}\right)$. It had positive weak correlation with harvesting index $(0.17)$ and harvesting date (0.16). But it was negatively correlated with the number of seeds per capsule $(-0.10)$ and 1000-seed weight $(-0.10)$ (Table 2$)$.

The number of secondary branches had highly significant correlation with the number of total branches $\left(0.95^{* *}\right)$, number of effective capsules per plant $\left(0.70^{* *}\right)$, plant height $\left(0.69^{* *}\right)$, number of tertiary branches $\left(0.68^{* *}\right)$, and stem thickness $\left(0.68^{* *}\right)$, seed yield ha ${ }^{-1}\left(0.66^{* *}\right)$, and biological yield $\left(0.34^{* *}\right)$. It had significant correlation with harvesting index $\left(0.29^{*}\right)$ and also negatively correlated with 1000 -seed weight $(-0.09)$ harvesting date $(-0.11)$ and the number of seeds per capsule $(-0.01)$ (Table 2$)$.

Tertiary branches had highly significant correlation with total branch $\left(0.76^{* *}\right)$, seed yield ha $^{-1}\left(0.49^{* *}\right)$, number of effective capsules per plant $\left(0.46^{* *}\right)$, plant height $\left(0.40^{* *}\right)$, and harvesting index $\left(0.35^{* *}\right)$; it had significant correlation with stem thickness $\left(0.29^{*}\right)$ and is positively correlated with biological yield (0.11) and the number of seeds per capsule $(0.07)$ and highly negatively correlated with harvesting date $\left(-0.53^{* *}\right)$ and weakly negatively correlated with thousandseed weight $(-0.14)$.

Total branch number was highly significantly correlated with most traits studied but negatively correlated with harvesting date $(-0.18)$, thousand-seed weight $(-0.14)$, and number of seeds per capsule $(-0.02)$. Stem thickness also showed highly significant correlation with plant height $\left(0.68^{* *}\right)$, number of effective capsules per plant $\left(0.59^{* *}\right)$, and seed yield $\mathrm{ha}^{-1}\left(0.52^{* *}\right)$ and significantly correlated with biological yield $\left(0.29^{*}\right)$ and positively correlated with the rest traits except the number of seeds per capsule $(-0.08)$ studied (Table 2).

Plant height had highly significant correlation with the number of effective capsules per plant $\left(0.76^{* *}\right)$, seed yield $\mathrm{ha}^{-1}\left(0.66^{* *}\right)$, and harvesting index $\left(0.37^{* *}\right)$. It had also positive correlation with harvesting date $(0.06)$ and negative correlation with number of seed per capsule $(-0.15)$ and 1000 -seed weight $(-0.09)$ (Table 2).

Days to harvest had a significant correlation with biological yield $\left(0.27^{*}\right)$ and 1000 -seed weight $(0.02)$, while it had a negative correlation with seed yield $\mathrm{ha}^{-1}(-0.21)$ and the number of seeds per capsule $(-0.19)$ and the number of effective capsules per plant $(-0.07)$, but it was highly negatively correlated with harvesting date $\left(-0.41^{*}\right)$. Biological yield had a highly significant correlation with the number of effective capsules per plant $\left(0.42^{* *}\right)$ while it was positively correlated with 1000 -seed weight ( 0.16$)$ but highly negatively correlated with harvesting index $\left(-0.53^{* *}\right)$ and negatively correlated with the number of seeds per capsule $(-0.09)$ (Table 2).

The number of effective capsules per plant had a highly significant correlation with seed yield ha ${ }^{-1}\left(0.83^{* *}\right)$ and also harvesting index $\left(0.36^{* *}\right)$, while it had highly negative correlation with the number of seeds per capsule $\left(-0.34^{* *}\right)$ and was negatively correlated with 1000 -seed weight $(-0.07)$ (Table 2). Therefore, increase in capsule number in a plant results in 1000-seed weight and seed number reduction of capsule and ultimately reduction in seed yield. This result agrees with the previous studies [17]. 


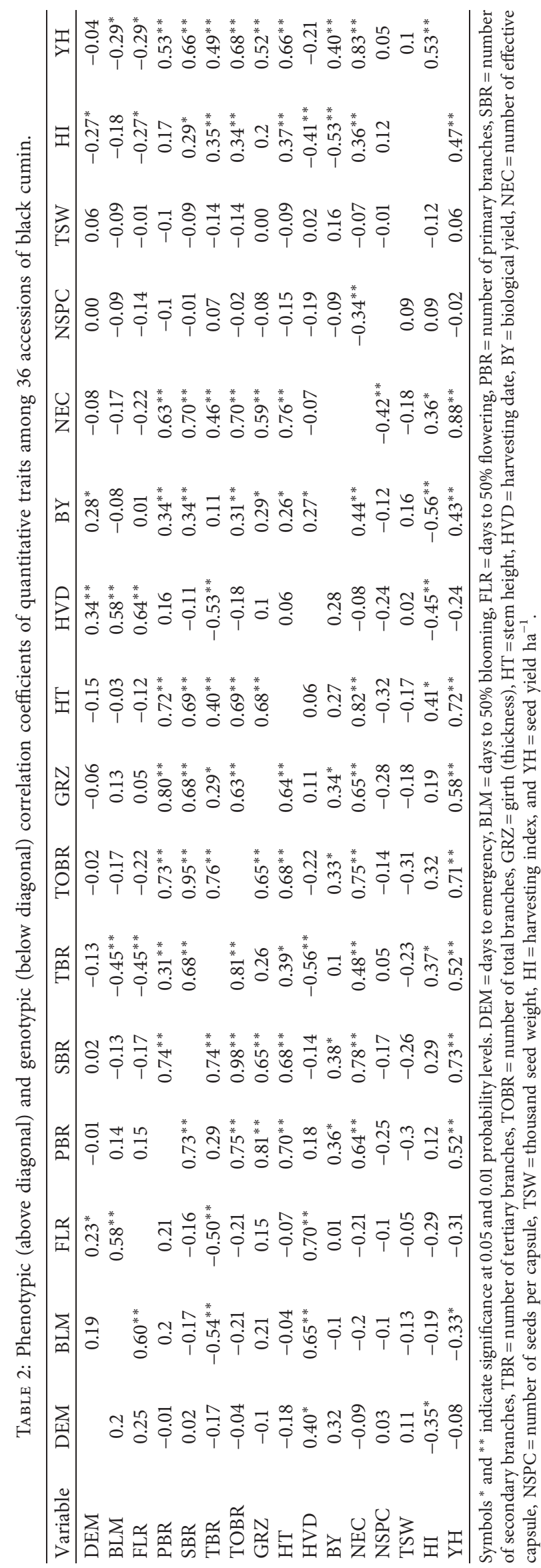


The number of seeds per capsule had positive correlation with harvesting index $(0.12)$ and seed yield $\mathrm{ha}^{-1}(0.05)$. It is also negatively correlated with 1000 -seed weight $(-0.01)$. Thousand-seed weight has a positive correlation with seed yield ha $\mathrm{h}^{-1}(0.10)$ but is negatively correlated with harvesting index (-0.08) (Table 2). In addition, harvesting index $\left(0.53^{* *}\right)$ has highly significant correlation with seed yield $\mathrm{ha}^{-1}$.

3.2. Genotypic Correlation Coefficients of 36 Accessions. The result of genotypic correlation coefficient analysis (Table 2 below diagonal) showed that seed yield ha ${ }^{-1}$ had a highly significant $(P<0.01)$ and positive correlation with the number of effective capsules per plant $\left(0.88^{* *}\right)$, secondary branches $\left(0.73^{* *}\right)$, plant height $\left(0.72^{* *}\right)$, total branches $\left(0.71^{* *}\right)$, stem thickness $\left(0.58^{* *}\right)$, primary branches $\left(0.52^{* *}\right)$, tertiary branches $\left(0.52^{* *}\right)$, harvesting index $\left(0.47^{* *}\right)$, and biological yield $\left(0.43^{* *}\right)$, but was negatively and significantly correlated with days to blooming, flowering, and days to maturity.

This shows that as the number of branches, plant height, and stem thickness increase, the seed yield ha ${ }^{-1}$ increases, but the number of days to which the crop reaches physiological maturity decreases because there were many more capsules on secondary and tertiary branches which did not bloom, flower, or mature at same time with capsules on primary branches and this delayed the stage of maturity. This finding is in line with previous studies [17-19]. In addition, the analysis result coincided with previous results [20], evaluating thirty-six local accessions of Ethiopian caraway, reported genotypically seed yield was positive and highly significant with the number of primary branches $\left(0.48^{* *}\right)$, secondary branches $\left(0.5^{* *}\right)$, number of umbel per plant $\left(0.8^{* *}\right)$, number of seeds per umbel $\left(0.98^{* *}\right)$, and plant height $\left(0.79^{* *}\right)$.

Days to emergence significantly $(P<0.05)$ correlated with days to harvest $\left(0.40^{*}\right)$, indicating that if the accessions which emerged early have a chance to harvest early, days to emergence had also a positive correlation with biological yield (0.32), 50\% flowering (0.25), blooming (0.20), thousand-seed weight $(0.11)$, number of seeds per capsule (0.03), and number of secondary branches (0.02) and also negative correlation with stem height $(-0.18)$, stem thickness $(-0.10)$, seed yield ha ${ }^{-1}(-0.08)$, tertiary branches $(-0.17)$, number of total branches per plant $(-0.04)$, and primary branches $(-0.01)$ but also significant and negative correlation with harvesting index $\left(-0.35^{*}\right)$. This is because late germinated plants do not have enough time to produce more branch number and did not have good stem thickness potential as well, and then if not enough branches were produced, there may not have a chance to produce sufficient effective capsules that can gain seeds; finally seed yield $\mathrm{ha}^{-1}$ become lower, which means harvesting index becomes also lower (Table 2).

Days to blooming had highly significant and positive correlation with days to harvest $\left(0.65^{* *}\right)$ and $50 \%$ flowering $\left(0.60^{* *}\right)$, while positively correlated with stem thickness (0.21) and the number of primary branches (0.20) (Table 2).
The result revealed that if days to bloom are shorter, then it can be harvested earlier because genotypes that bloomed earlier can flower faster and mature timely without facing environmental challenges such as moisture stress. It had highly significant and negative correlation with tertiary branches $\left(-0.54^{* *}\right)$ and negatively significant correlation with amount of seed yield $\mathrm{ha}^{-1}\left(-0.33^{*}\right)$. And also days to blooming had negative correlation with the number of total branches per plant $(-0.21)$, the number of effective capsules per plant $(-0.20)$, the number of secondary branches per plant $(-0.17)$, 1000-seed weight $(-0.13)$, biological yield $(-0.10)$, the number of seeds per capsule $(-0.10)$, and plant height (-0.04). These might happen due to late blooming, which caused facing of unfavorable environmental conditions for the development of the crop. Late bloom accessions cannot flower completely because in nature black cumin flowering is not uniform on a single plant's branches. So, there might be a probability of flowerless tertiary branches and abortion of flowers due to harsh reasons like moisture stress, at the end, resulting in seed yield reduction due to late blooming.

Days to $50 \%$ flowering had a highly significant correlation with harvesting date $\left(0.70^{* *}\right)$. It had positive correlation with primary branch (0.21), stem thickness (0.15), and biological yield $(0.01)$ but was highly negatively correlated with tertiary branch $\left(-0.50^{* *}\right)$ and negatively correlated with other traits studied. This showed that in nature black cumin flower starts from primary branches; then secondary and tertiary branches consecutively here at tertiary branch 50\% flowering did not appear the same as the primary branches to mature once (Table 2).

The number of primary branches had highly significant correlation with stem thickness $\left(0.81^{* *}\right)$, total branches $\left(0.75^{* *}\right)$, number of secondary branches $\left(0.73^{* *}\right)$, plant height $\left(0.70^{* *}\right)$, number of effective capsules per plant $\left(0.64^{* *}\right)$, and seed yield $\mathrm{ha}^{-1}\left(0.52^{* *}\right)$. It had significant correlation with biological yield $\left(0.36^{*}\right)$ and also positive weak correlation with the number of tertiary branches (0.29), harvesting date (0.18), and harvesting index (0.12) but negative correlation with 1000 -seed weight $(-0.30)$, and the number of seeds per capsule $(-0.25)$ (Table 2$)$.

the number of secondary branches had highly significant correlation with total branch number $\left(0.98^{* *}\right)$, number of effective capsules per plant $\left(0.78^{* *}\right)$, number of tertiary branches $\left(0.74^{* *}\right)$, plant height $\left(0.68^{* *}\right)$, seed yield ha ${ }^{-1}$ $\left(0.73^{* *}\right)$, and stem thickness $\left(0.65^{* *}\right)$. It had significant correlation with biological yield $\left(0.38^{*}\right)$ and positive correlation with harvesting index $(0.29)$ and also negative correlation with 1000 -seed weight $(-0.26)$, number of seeds per capsule, and $(-0.17)$, and harvesting date $(-0.14)$ (Table 2).

Tertiary branch number had highly significant correlation with seed yield $\mathrm{ha}^{-1}\left(0.52^{* *}\right)$, number of effective capsules per plant $\left(0.48^{* *}\right)$, and total branch number $\left(0.81^{* *}\right)$. It had significant correlation with plant height $\left(0.39^{*}\right)$ and harvesting index $\left(0.37^{*}\right)$. And also, it had positive correlation with stem thickness (0.26), biological yield (0.10), and the number of seeds per capsule (0.05) but high negative correlation with date to harvest $\left(-0.56^{* *}\right)$ and 
weak and negative correlation with 1000 -seed weight $(-0.23)$ (Table 2).

The total branch number had highly significant correlation with the number of effective capsules per plant $\left(0.75^{* *}\right)$, stem thickness $\left(0.65^{* *}\right)$, and plant height $\left(0.68^{* *}\right)$. It had significant positive correlation with biological yield $\left(0.33^{*}\right)$ but was positively correlated with harvesting index (0.32), while it had weak negative correlation with 1000 -seed weight $(-0.31)$ harvesting date $(-0.22)$ and the number of seeds per capsule $(-0.14)$ (Table 2$)$.

Stem thickness (girth) had highly significant correlation with the number of effective capsules per plant $\left(0.65^{* *}\right)$, plant height $\left(0.64^{* *}\right)$, and seed yield ha ${ }^{-1}\left(0.58^{* *}\right)$. It had significant correlation with biological yield $\left(0.34^{*}\right)$ and was positively correlated with harvesting index (0.19) and harvesting date (0.11). In addition, it was negatively correlated with the number of seeds per capsule $(-0.28)$ and 1000-seed weight $(-0.18)$. Plant height had highly significant correlation with the number of effective capsules per plant $\left(0.82^{* *}\right)$ and seed yield $\mathrm{ha}^{-1}\left(0.72^{* *}\right)$. It had also significant correlation with harvesting index $\left(0.41^{*}\right)$, positive correlation with biological yield (0.27) and harvesting date (0.06), and negative correlation with the number of seeds per capsule $(-0.32)$ and 1000 -seed weight $(-0.17)$ (Table 2).

Days to harvest had a positive correlation with biological yield (0.28) and 1000-seed weight (0.02). It had a highly negative correlation with harvesting index $\left(-0.45^{* *}\right)$ and negative correlation with the number of seeds per capsule $(-0.24)$, seed yield per $\mathrm{ha}^{-1}(-0.24)$, and the number of effective capsules per plant $(-0.08)$ (Table 2$)$.

Biological yield had a highly significant correlation with the number of effective capsules per plant $\left(0.44^{* *}\right)$ and seed yield $\mathrm{ha}^{-1}\left(0.43^{* *}\right)$ and positive correlation with 1000 -seed weight $(0.16)$ but highly negative correlation with harvesting index $\left(-0.56^{* *}\right)$ and negative correlation with the number of seeds per capsule $(-0.12)$ (Table 2$)$.

The number of effective capsules per plant had a highly significant correlation with seed yield ha ${ }^{-1}\left(0.88^{* *}\right)$ and it had significant correlation with harvesting index $\left(0.36^{*}\right)$. It had highly negative correlation with the number of seeds per capsule $\left(-0.42^{* *}\right)$ and negative correlation with 1000 -seed weight $(-0.18)$ (Table 2$)$.

The number of seeds per capsule had positive correlation with 1000-seed weight (0.09) and harvesting index (0.09) and negative correlation with seed yield $\mathrm{ha}^{-1}(-0.02)$. Thousand-seed weight has a positive correlation with seed yield $\mathrm{ha}^{-1}(0.06)$ but negative correlation with harvesting index $(-0.12)$.

\subsection{Phenotypic Direct and Indirect Effect of Various Char-} acters on Black Cumin Seed Yield. Phenotypic correlation of the characters was then partitioned in path coefficient, with a view to identify important characters having direct effect on seed yield ha ${ }^{-1}$ (Table 3 ). Harvesting index (0.833), biological yield (0.739), and the number of effective capsules per plant (0.235) exerted high and favorable direct effects on seed yield. The number of total branch per plant (0.051), stem thickness (0.035), and number of primary branches per plant
(0.003) had some positive but weak direct influence on seed yield $\mathrm{ha}^{-1}$. These direct effects, therefore, indicate that other variables kept constant; the merits of harvesting index, biological yield, number of effective capsules per plant, number of total branches per plant, stem thickness, and number of primary branches per plant for improving seed yield significantly due showed the highest phenotypic direct effect. The same result was reported [8], where the most direct effect of traits on yield was obtained from biological yield (0.778), followed by the number of capsules per plant (0.245).

However, from those traits exerted, the highest negative phenotypic direct effect on seed yield was recorded for plant height $(-0.072)$, days to blooming $(-0.039)$, number of tertiary branches per plant $(-0.029)$, and days to flowering $(-0.016)$ followed by the number of secondary branches $(-0.008)$ that showed minor negative direct effect with seed yield $\mathrm{ha}^{-1}$ (Table 3 ).

Harvesting index 0.833 and biological yield $\mathrm{ha}^{-1}(0.739)$ exhibited the highest positive direct effect on seed yield $\mathrm{ha}^{-1}$. However, harvesting index also showed the highest negative indirect effect on seed yield ha ${ }^{-1}$ via biological yield $(-0.389)$, whereas the highest positive indirect effects were also recorded for this trait via plant height (0.308). The result of this study is in agreement with that of the previous study [21], that the phenotypic path coefficient analysis of biomass per plant (0.879) and harvest index per plant $(0.258)$ exerted high and favorable direct effects on seed yield per plot.

Therefore, it is evident from the result of this study that high consideration should be given for harvesting index, biological yield, and number of effective capsules per plant, followed by the number of total branches per plant, stem thickness, and number of primary branches per plant.

The genotypic direct and indirect effect of different characters on seed yield $\mathrm{ha}^{-1}$ is presented in Table 4 . The number of secondary branches (1.094) had maximum positive direct effect on seed yield $\mathrm{ha}^{-1}$, followed by harvesting index (0.839), biological yield (0.765), number of tertiary branches (0.649), number of primary branches (0.487), number of effective capsule per plant (0.325), and stem thickness $(0.053)$. This indicated that a slight increase in one of the above traits may directly contribute to seed yield. Therefore, selecting genotypes having more number of secondary branches, harvesting index, high biological yield, more number of primary and tertiary branches, and also more number of effective capsules per plant and thick stem thickness could be used to improve seed yield in black cumin genotypes as a result of their direct effect on yield.

Similar to this study, [22] observed that the number of branches had the highest and positive direct effect on seed yield. In the previous study, [8] also reported the most direct effect of traits on yield were shown on biological yield (0.778) followed by the number of capsules per plant (0.245).

The genotypic path coefficient analysis revealed that the characters that exerted the highest negative genotypic direct effect on seed yield were recorded for number of total branches $(-1.985)$, plant height $(-0.131)$, and days to blooming $(-0.043)$. 
TABLe 3: Phenotypic direct (bold) and indirect effect (off diagonal) of 16 traits on grain yield.

\begin{tabular}{lcccccccccccc}
\hline & BLM & FLR & PBR & SBR & TBR & TOBR & GRZ & HT & BY & NEC & HI & RP \\
\hline BLM & $-\mathbf{0 . 0 3 9}$ & -0.010 & 0.000 & 0.001 & 0.013 & -0.009 & 0.005 & 0.002 & -0.062 & -0.040 & -0.153 & -0.291 \\
FLR & -0.023 & $-\mathbf{0 . 0 1 6}$ & 0.000 & 0.001 & 0.013 & -0.011 & 0.002 & 0.008 & 0.008 & -0.051 & -0.224 & -0.292 \\
PBR & -0.006 & -0.002 & $\mathbf{0 . 0 0 3}$ & -0.006 & -0.009 & 0.038 & 0.028 & -0.052 & 0.249 & 0.147 & 0.141 & 0.531 \\
SBR & 0.005 & 0.003 & 0.002 & $-\mathbf{0 . 0 0 8}$ & -0.019 & 0.049 & 0.024 & -0.050 & 0.252 & 0.165 & 0.238 & 0.660 \\
TBR & 0.018 & 0.007 & 0.001 & -0.005 & $-\mathbf{0 . 0 2 9}$ & 0.039 & 0.010 & -0.029 & 0.082 & 0.108 & 0.290 & 0.492 \\
TOBR & 0.007 & 0.004 & 0.002 & -0.008 & -0.022 & $\mathbf{0 . 0 5 1}$ & 0.022 & -0.050 & 0.228 & 0.164 & 0.280 & 0.678 \\
GRZ & -0.005 & -0.001 & 0.003 & -0.006 & -0.008 & 0.032 & $\mathbf{0 . 0 3 5}$ & -0.049 & 0.212 & 0.139 & 0.169 & 0.521 \\
HT & 0.001 & 0.002 & 0.002 & -0.006 & -0.011 & 0.035 & 0.024 & $-\mathbf{0 . 0 7 2}$ & 0.195 & 0.178 & 0.308 & 0.656 \\
BY & 0.003 & 0.000 & 0.001 & -0.003 & -0.003 & 0.016 & 0.010 & -0.019 & $\mathbf{0 . 7 3 9}$ & 0.098 & -0.438 & 0.404 \\
NEC & 0.007 & 0.004 & 0.002 & -0.006 & -0.013 & 0.036 & 0.021 & -0.055 & 0.308 & $\mathbf{0 . 2 3 5}$ & 0.297 & 0.834 \\
HI & 0.007 & 0.004 & 0.001 & -0.002 & -0.010 & 0.017 & 0.007 & -0.027 & -0.389 & 0.084 & $\mathbf{0 . 8 3 3}$ & 0.525 \\
\hline
\end{tabular}

Residual effect $=0.253933$. BLM $=$ days to $50 \%$ blooming, FLR $=$ days to $50 \%$ flowering, $\mathrm{PBR}=$ number of primary branches, $\mathrm{SBR}=$ number of secondary branches, $\mathrm{TBR}=$ number of tertiary branches, $\mathrm{TOBR}=$ number of total branches, GRZ = girth (thickness), HT=stem height, BY= biological yield, $\mathrm{NEC}=$ number of effective capsules per plant, $\mathrm{HI}=$ harvesting index, $\mathrm{YH}=$ seed yield $\mathrm{ha}^{-1}$, and $\mathrm{RP}=$ phenotypic correlation.

TABLE 4: Genotypic path analysis of the direct (bold) and indirect (off diagonal) effects of 16 traits on seed yield.

\begin{tabular}{lccccccccccc}
\hline & BLM & PBR & SBR & TBR & TOBR & GRZ & HT & BY & NEC & HI & RG \\
\hline BLM & $-\mathbf{0 . 0 4 3}$ & 0.098 & -0.182 & -0.349 & 0.426 & 0.011 & 0.005 & -0.074 & -0.065 & -0.161 & -0.334 \\
PBR & -0.009 & $\mathbf{0 . 4 8 7}$ & 0.803 & 0.189 & -1.486 & 0.043 & -0.092 & 0.279 & 0.210 & 0.099 & 0.522 \\
SBR & 0.007 & 0.357 & $\mathbf{1 . 0 9 4}$ & 0.477 & -1.949 & 0.035 & -0.089 & 0.295 & 0.253 & 0.247 & 0.728 \\
TBR & 0.023 & 0.142 & 0.805 & $\mathbf{0 . 6 4 9}$ & -1.610 & 0.014 & -0.052 & 0.080 & 0.156 & 0.311 & 0.518 \\
TOBR & 0.009 & 0.364 & 1.075 & 0.526 & $-\mathbf{1 . 9 8 5}$ & 0.035 & -0.089 & 0.254 & 0.245 & 0.272 & 0.706 \\
GRZ & -0.009 & 0.394 & 0.711 & 0.169 & -1.287 & $\mathbf{0 . 0 5 3}$ & -0.084 & 0.256 & 0.213 & 0.162 & 0.579 \\
HT & 0.002 & 0.343 & 0.742 & 0.256 & -1.347 & 0.034 & $-\mathbf{0 . 1 3 1}$ & 0.210 & 0.266 & 0.345 & 0.720 \\
BY & 0.004 & 0.177 & 0.421 & 0.068 & -0.659 & 0.018 & -0.036 & $\mathbf{0 . 7 6 5}$ & 0.144 & -0.473 & 0.429 \\
NEC & 0.009 & 0.314 & 0.850 & 0.311 & -1.496 & 0.035 & -0.107 & 0.338 & $\mathbf{0 . 3 2 5}$ & 0.301 & 0.880 \\
HI & 0.008 & 0.058 & 0.323 & 0.241 & -0.643 & 0.010 & -0.054 & -0.432 & 0.117 & $\mathbf{0 . 8 3 9}$ & 0.466 \\
\hline
\end{tabular}

Residual effect $=0.242268$. BLM $=$ days to $50 \%$ blooming, $\mathrm{PBR}=$ number of primary branches, $\mathrm{SBR}=$ number of secondary branches, $\mathrm{TBR}=$ number of tertiary branches, TOBR = number of total branches, GRZ = girth (thickness), $\mathrm{HT}=$ stem height, $\mathrm{BY}=$ biological yield, NEC = number of effective capsules per plant, $\mathrm{HI}=$ harvesting index, $\mathrm{YH}=$ seed yield $\mathrm{ha}^{-1}$, and $\mathrm{RG}=$ genotypic correlation.

The number of total branches per plant also showed the highest indirect negative effects on seed yield $\mathrm{ha}^{-1}$ via secondary branches and number of tertiary branches (Table 4). It had also considerably indirect negative effects through the number of effective capsules per plant, number of primary branches, plant height, stem thickness, and negligible negative indirect effects through biological yield. The number of total branches also scored considerably small positive indirect effects via days to blooming.

The residual effect $(0.242268)$ indicates that characters, which are included in the genotypic path analysis, explained $75.8 \%$ of the total variation in seed yield in which the numbers of traits chosen for the study were appropriate for yield improvement in black cumin; the remaining $24.2 \%$ were the contribution of other factors, such as traits not studied.

\section{Conclusion}

Seed yield was positively and highly correlated with primary branches, secondary branches, tertiary branch, total branches, stem thickness, plant height, biological yield, number of effective capsules per plant, and harvesting index. Hence, selection criteria should consider all these characters for the improvement of black cumin yield.

But it was negatively and significantly correlated with days to blooming and days to $50 \%$ flowering and days to harvest at both genotypic and phenotypic levels. It indicates a genotype which had all those traits contributed for high seed yield.

On the basis of both genotypic and phenotypic path coefficient analysis result, harvesting index, biological yield, number of effective capsules per plant, stem thickness, and number of primary branches showed positive direct effect on seed yield. The favorable direct effects of these traits on black cumin seed yield indicate that other variables kept constant and improvement of these traits will increase grain yield. Therefore, these traits should be kept in mind in the future breeding program of black cumin.

\section{Data Availability}

All data are available from the corresponding author upon request.

\section{Conflicts of Interest}

The authors declare that they have no conflicts of interest.

\section{References}

[1] E. A. Weiss, Spice Crops, CABI, New York, NY, USA, 2002.

[2] S. H. Khan, M. A. Anjum, A. Parveen, T. Khawaja, and N. M. Ashraf, "Effects of black cumin seed (Nigella sativa L.) 
on performance and immune system in newly evolved crossbred laying hens," Veterinary Quarterly, vol. 33, no. 1, pp. 13-19, 2013.

[3] M. S. Iqbal, A. Ghafoor, and A. S. Qureshi, "Evaluation of Nigella sativa L. for genetic variation and ex-situ conservation," Pakistan Journal of Botany, vol. 42, no. 4, pp. 24892495, 2010.

[4] L. Shewaye, "Antifungal substances from essential oils," Ph.D. thesis, Addis Ababa University, Addis Ababa, Ethiopia, 2012.

[5] K. Ghaznavi, "Tibbe-e-nabvi aur jadid science, al-faisal nasheeran wa tajeera-e-kutab," Urdu Bazar Lahore, Pakistan, vol. 1, pp. 228-236, 1991.

[6] V. A. Parthasarathy, B. Chempakam, and T. J. Zachariah, Chemistry of Spices, p. 41, CABI, Wallingford, UK, 2008.

[7] M. A. Rabbani, A. Ghafoor, and M. S. Masood, "NARCkalonji: an early maturing and high yielding variety of Nigella sativa released for cultivation in Pakistan," Pakistan Journal of Botany, vol. 43, pp. 191-195, 2011.

[8] K. Bardideh, D. Kahrizi, and M. E. Ghobadi, "Character association and path analysis of black cumin (Nigella sativa L.) genotypes under different irrigation regimes," Notulae Scientia Biologicae, vol. 5, no. 1, pp. 104-108, 2013.

[9] S. Sultana, H. M. Asif, N. Akhtar, A. Iqbal, H. Nazar, and R. U. Rehman, "Nigella sativa: monograph," Journal of Pharmacognosy and Phytochemistry, vol. 4, no. 4, pp. 103-106, 2015.

[10] P. C. M. Jansen, Spices, Condiments and Medicinal Plants in Ethiopia, Their Taxonomy and Agricultural Significance, Centre for Agricultural Publishing and Documentation, Wageningen, Netherland, 1981.

[11] M. Kashif and I. Khalq, "Heritability, correlation and path coefficient analysis for some metric traits in wheat," International Journal of Agriculture and Biology, vol. 6, no. 1, pp. 138-142, 2004.

[12] O. Aliyu, "Phenotypic correlation and path coefficient analysis of nut yield and yield components in cashew (Anacardium occidentale L.)," Silvae Genetica, vol. 55, no. 1-6, pp. 19-24, 2006.

[13] E. G. Seyum, "Influence of plant spacing and date of sowing on yield and yield components of two snap bean (Phaseolus vulgaris L.) varieties in Jimma, southwestern Ethiopia," Merit Research Journal of Agricultural Science and Soil Science, vol. 2, no. 7, pp. 086-095, 2014.

[14] Y. Ebrie, N. Amsalu, M. Ali, and G. Merkebu, "Effect of nitrogen and phosphorus fertilizers on growth, yield and yield components of black cumin (Nigella sativa L.) at Konta district, south west Ethiopia," Journal of Agronomy, vol. 14, no. 3, p. 112, 2015

[15] K. A. Gomez and A. A. Gomez, Statistical Procedures for Agricultural Research, Wiley, Hoboken, NJ, USA, 1984.

[16] SAS, Statistical Analysis System Version 9.3, SAS Institute Inc., Cary, NC, USA, 2017.

[17] M. Faravani, S. A. Razavi, and M. Farsi, "Study of variation in some agronomic and anatomic characters of Nigella sativa landraces in Khorasan," Iranian Journal of Medicinal and Aromatic Plants, vol. 22, no. 3, pp. 193-197, Article ID 33, 2006.

[18] L. F. D’Antuono, A. Moretti, and A. F. S. Lovato, "Seed yield, yield components, oil content and essential oil content and composition of Nigella sativa L. and Nigella damascena L." Industrial Crops and Products, vol. 15, no. 1, pp. 59-69, 2002.

[19] S. P. Singh and P. Rajendra, "Path coefficient analysis of seed yield in coriander," International Journal of Agricultural Science, vol. 1, no. 1, pp. 98-61, 2005.
[20] S. Hussen, K. W. Tsadik, and G. Alemaw, "Genetic variability assessment of Ethiopian caraway (Trachyspermum ammi L. Sprague ex turrill) genotypes at mersa, Ethiopia," Advances in Life Science and Technology, vol. 10, p. 8, 2013.

[21] B. Na'ol, "Genetic variability and association among seed yield and yield related traits in Ethiopian mustard (Brassica carinata A. Braun) at Haramaya university campus, Raare site, eastern Ethiopia," M.Sc. thesis, p. 37, Haramaya University, Dire Dawa, EthiopiaHaramaya University, 2015.

[22] S. Salehi, A. Rokhzadi, G. Noormohammadi, S. M. Mirhadi, and A. R. Golparvar, "Genetic improvement of quantity/ quality yield of black cumin (Nigella sativa L.) ecotypes cultivated in Iran climatic conditions," Journal of Herbal Drugs (An International Journal on Medicinal Herbs, vol. 6, no. 4, pp. 187-193, 2016. 